\section{Curiosity first, applications later}

\author{
Tebello Nyokong speaks to Robert Berold and Janice Limson about her \\ career as a chemist
}

$\mathbf{T}$ EBELLO NYOKONG, WHO HOLDS A research chair in medicinal chemistry and nanotechnology at Rhodes University, has become the first South African scientist to win the L'Oréal-UNESCO award for women in science, in the physical sciences. Only one laureate is selected from each of five world regions, and Nyokong is the 2009 laureate for Africa and the Arab states. She and the winners from the other four regions travel to Paris in March to each accept the award and a generous prize of close to R1 million.

Nyokong researches the group of highly coloured compounds called phthalocyanines which are related to porphyrins - the dye used in blue jeans is porphyrin-based, as is haemoglobin, which gives the red colour to blood. These compounds have widespread application as catalysts of chemical and biological reactions, and have been used as potent therapies for cancer, as highly sensitive sensors for detecting pathogens, and in the cleaning of polluted water. 'I fell in love with phthalocyanines,' she says. 'They are well behaved, stable, and very colourful-they are beautiful molecules. For my Ph.D. I was trying to investigate whether we could make them water soluble.'

At that stage there was no thought of applications: 'But you know, most research that goes anywhere is not based on applications. Curiosity-driven research is how most discoveries are made. The applications come later.'

By altering the chemical structure of phthalocyanines-by changing their metal centres, adding substituents, or coupling them with enzymes or nanoparticles such as quantum dots-it becomes possible to finely tune and manipulate their properties. The research by Nyokong and her team into early warning systems for diseases and environmental toxins has resulted in the development of several sensors, including the most sensitive detection system yet developed for the neurotransmitter nitric oxide.

One application is in combating cancer, and here Nyokong's research takes a three-tiered approach. The first tier, sensor research, aims to detect and target cancercausing agents before they can do any harm to the human body. The next tier, targeting of the specific biological markers of certain cancers, allows for early diagnosis. The third tier is cancer treatment, and porphyrin-based cancer drugs developed by Nyokong and her team over several years are currently undergoing pre-clinical trials in South Africa.

More recently, with the opportunities afforded by nanostructured materials, this research has entered a new phase, combining the phenomenal physical and chemical properties of nanostructures with the catalytic properties of synthetic porphyrin molecules. This work is an extension of photodynamic therapy-the use of specially developed dyes to direct deadly light onto cancer cells-which is being researched worldwide as an alternative to chemotherapy. In photodynamic therapy, the dye is injected into the bloodstream or, for skin cancer, applied directly to the skin.
When photodynamic therapy is combined with quantum dots, cancer cells can be killed even more efficiently. Quantum dots are particles in the nano range which can be connected to biological molecules, and so can be directed to targeted biological systems for imaging. They can absorb and re-emit light, so once they are in the target area, their fluorescence can then be used to detect tumours.

Nyokong has been one of the very first proponents of the phthalocyanine-nanostructure hybrid approach, and one of the first to extend the field beyond photodynamic therapy to sensing systems. Her breakthrough came when she was able to chemically couple phthalocyanines either with nanostructures such as multi-walled and single-walled carbon nanotubes, or directly to enzymes. 'Someone from the National Laser Centre called me at 10 pm one night-they wanted to come the next day to discuss the possibility of loaning me some lasers. I knew this was a great opportunity, because I needed lasers to study the molecules we make in the lab.' Laser technology has since significantly improved her research in photodynamic therapy.

Nyokong intends to invest some of her

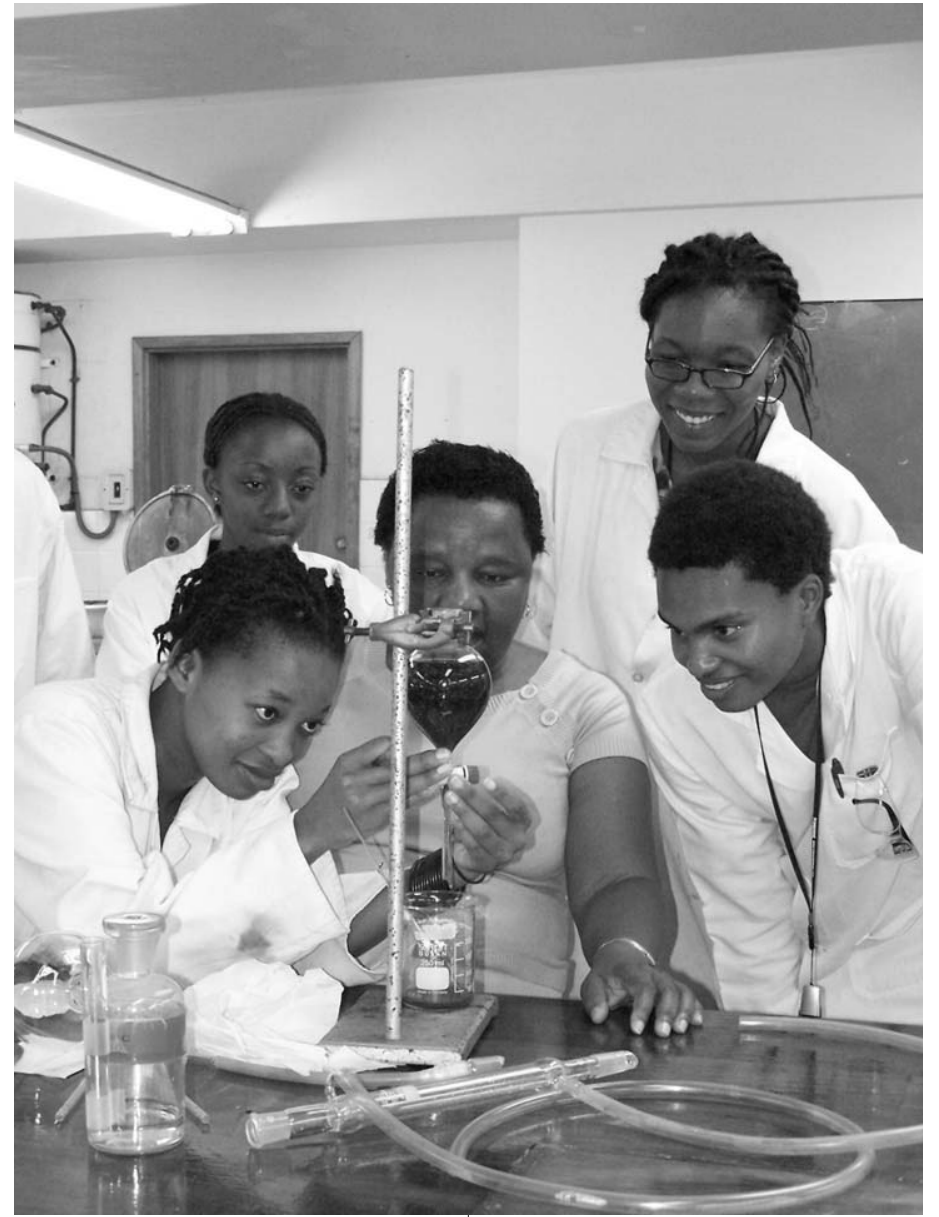

Tebello Nyokong (centre) leading by example. 
prize into seeing these compounds successfully through the developmental, trial and safety testing stages so that they could become available on the market in the years to come: 'All the trials take forever-there are so many restrictions and conditions. Someone else can do that. But we've found one drug that is really going to be a big one. We've tested it on cells and it's brilliant. We are still doing more trials before we patent it, but we really think it's going to be a world-class South African drug.'

Another branch of Nyokong's research is photosensitised oxidation for pollution control. Photochemical destruction of certain pollutants, such as chlorinated phenols and other pesticides, is commonly done with ultraviolet light. However, the products of photodegradation after such ultraviolet treatment can be more toxic than the parent compounds. A possible alternative is photosensitised oxidation. Nyokong is investigating the use of phthalocyanines as photosensitisers to transform chlorinated phenols and other pollutants into less harmful products.

Nyokong's own story speaks eloquently of her tremendous commitment and passion for science. She was raised in Sharpeville, but her family left for Lesotho soon after the infamous 1960 massacre. Her Pan-Africanist father believed strongly in education for girls, but at the same time his three daughters were expected to contribute by helping out in the family's construction business, planting, weeding and harvesting the extensive vegetable garden, and cleaning the house.

Tebello only started school when she was eight years old. 'I was staying with my paternal grandmother in the Free State. In those days you were not permitted to enter primary school until you could reach over your head and touch your opposite ear, using your hand. I could only do this when I was eight years old. Having a short arm was not good for one's intellectual development!' She went on to school in Lesotho, and remembers fondly the devotion and discipline of her (mostly female) teachers. It was a poor school, with parents and churches having to build classrooms, and some classes held under a tree. She saw that with dedicated teachers 'one can learn even in very difficult situations. Yes it would be nice to have good classrooms, but if they are not there, learning can go on! We were even very proud of our classroom under the tree.'

She excelled at science, but a career in chemistry was not her first choice. 'To be honest I did not even know what jobs one could get as a chemistry graduate. Like many young people, I wanted to be a doctor.' This ambition had to be shelved because her father became too ill for her to take up offers of a dentistry or medical scholarship abroad. So she decided to study chemistry in Lesotho and become a high school teacher. Then she won a postgraduate scholarship in Canada. 'By that time I loved chemistry fully, and I began to see that even though doctors cure patients, it is chemists that develop the medicines. Being a doctor was no longer so important to me.'

While still at university, Nyokong married and had two children. She admits that being a young mother while studying for her Ph.D. and working as a cash-strapped teaching assistant was 'very difficult'. Nor did these difficulties end when her doctorate was completed. Research was a lonely road. 'I had no one to talk to among my peers when things went wrong with my research or even when I got very excited about my research. I experienced-and still experienceacademic loneliness.'

Racism and sexism were additional hurdles when she arrived at Rhodes as a lecturer in 1992. 'Clearly Rhodes chemistry students had never been taught by a black person, let alone a black woman. There were some difficulties at the beginning which I soon overcame. But one had to be very firm!' By 2001 she was a full professor, and she has now trained close to 30 M.Sc. and Ph.D. students. 'Many of these children (I can call them children because I'm older now) come from rural backgrounds. I think they gravitate towards me because they also know I've come from there.' Some have gone on to become lecturers in chemistry, some have emigrated, and some are in industry. 'I get tired, though, when I see how many graduates are money-driven. You should just work for what you are paid for. It's all about commitment.'

Nyokong now heads the new Nanotechnology Innovation Centre for medical sensors: the biggest single research investment in the history of Rhodes. Linked to other nanotechnology centres in the country, it is designed to bridge the gap between research and the market. Developing skills and human resource capacity in nanotechnology in South Africa is the centre's top priority, and it will conduct both fundamental and applied research towards the development of sensors for early detection of disease. The centre will investigate new approaches in molecular immobilisation, using metal- and carbon-based nanoparticles and nanotubes. It will develop sensors for the rapid detection of medically important molecules (such as amino acids, thiols, neurotransmitters), and sensors for monitoring biological toxins.

Peter Clayton, deputy vice-chancellor for research at Rhodes says, 'What Tebello Nyokong has achieved is quite staggering. She literally oozes passion for sciencedoing it, teaching it, promoting it, financing it, and applying it.'

Robert Berold is a writer based in Grahamstown.

Janice Limson is a senior lecturer in biotechnology at Rhodes University. 